\title{
Waterbowls: Reducing Impacting Droplet Interactions by Momentum Redirection
}

\author{
Supplementary Information \\ Henri-Louis Girard, Dan Soto, and Kripa K. Varanasi* \\ Department of Mechanical Engineering, MIT, Cambridge, MA 02139, USA. \\ *Corresponding author. Email: varanasi@mit.edu
}

\section{$\underline{\text { Rain drop size distribution }}$}

The rain droplets generated by the AATCC standard showerhead spreader follow the size distribution shown on Figure S1. The mean drop diameter was $\bar{D}=3.25 \mathrm{~mm}$ with a standard deviation of $0.72 \mathrm{~mm}$. The velocity of the droplets was highly uniform with a mean of $\bar{v}=2.42 \mathrm{~m} / \mathrm{s}$ and a standard deviation of $0.16 \mathrm{~m} / \mathrm{s}$. These properties lead to a mean Weber number $\overline{W e}=133$. 

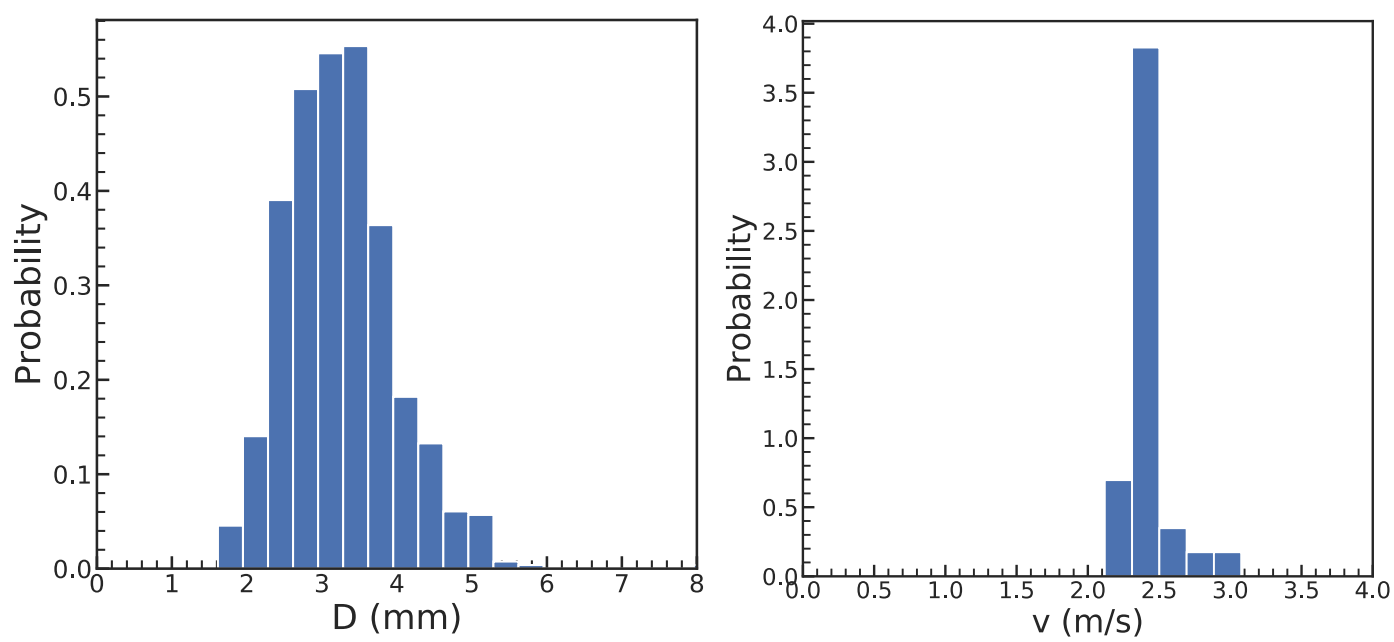

Figure S1. Probability density normalized histograms of the distribution of droplet diameter (left) and droplet velocity (right). 